\title{
GESTÃO E COOPERAÇÃO EM REDES
}

Os estudos sobre redes buscam compreender a dinâmica social que, junto com a perspectiva econômica, podem explicar o desenvolvimento de articulações organizacionais e interorganizacionais em múltiplas escalas. A lógica da composição das redes e do enraizamento incorpora a idéia da mobilidade presente na sociedade contemporânea. Também amplia a compreensão das relações que as empresas precisam para se reproduzir e das interfaces produtivas que conectam atores dispersos. Adicionalmente, contribuem para definir estratégias de cooperação, mecanismos de governança e políticas públicas que visem ao desenvolvimento local e territorial. A complexidade que permeia esse campo de conhecimento permite conceber as redes como forma organizacional, estratégia ou metodologia de análise que pode captar e intervir na estrutura e nos mecanismos de gestão de redes intra e interorganizacionais. A professora Zilma Borges, da FGV-EAESP, apresenta obras que auxiliam no entendimento do tema.
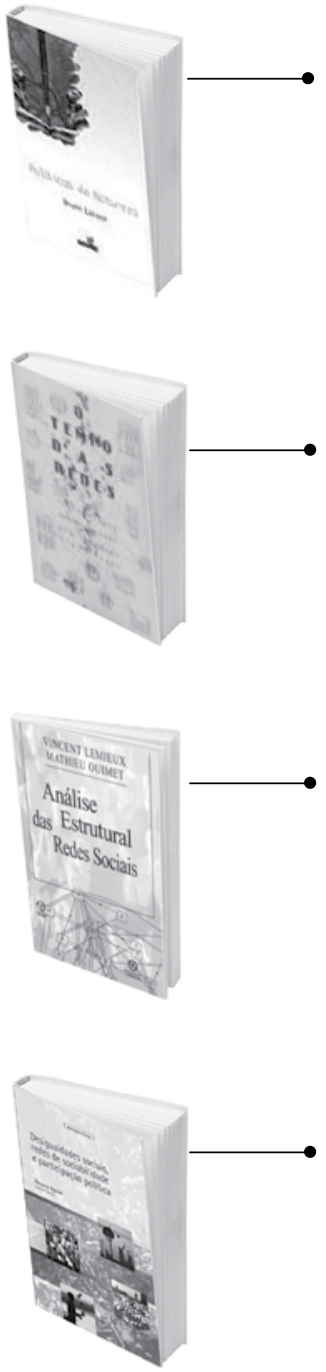

O TEMPO DAS REDES. Fábio Duarte; Queila Souza; Carlos Quandt (Orgs). São Paulo: Perspectiva, 2008. 264 p.

A disseminação da concepção de redes como paradigma de comportamento e perspectiva de análise política, social e econômica exige novos esforços metodológicos para a compreensão desses fenômenos de forma simultânea. Este livro apresenta debates sobre temas contemporâneos e reúne autores reconhecidos com análises desenvolvidas a partir do conceito de rede. Nele se relacionam fatos, acontecimentos e percepções integrados entre si e mapeados segundo uma estrutura relacional capaz de identificar os fenômenos em vários níveis de abordagem, o que permite uma visão ao mesmo tempo panorâmica e vertical.

ANÁLISE ESTRUTURAL DAS REDES SOCIAIS. Vincent Lemieux; Mathieu Ouimet. Porto Alegre: Instituto Piaget, 2008. 128 p.

A análise estrutural das redes sociais tem uma abordagem interdisciplinar assentada no pressuposto de que os atores sociais se caracterizam mais pelas suas relações do que pelos seus atributos, como gênero, idade e classe social. Os laços formados permitem analisar esses fenômenos, caracterizando redes sociométricas, redes de apoio e de mobilização tanto nas conexões entre empresas como nas relações formadas no espaço público. Após explicar o tratamento de dados da análise estrutural, os autores apresentam estudos de caso analisados com a ajuda de teorias e conceitos discutidos na obra.

DESIGUALDAES SOCIAIS, REDES DE SOCIABILIDADE E PARTICIPAÇÃO POLÍTICA. Neuma Aguiar (Org). Belo Horizonte: Editora UFMG. 2007. 297 p.

Utilizando a perspectiva das redes, este livro demonstra a importância de vários aspectos da estratificação da sociedade, como educação e outros recursos culturais, mercado de trabalho, recursos econômicos e uma variedade de novos indicadores empregados nas características do espaço urbano no Brasil. Com base em pesquisa empírica e na utilização de amostragem científica, traz informações consistentes sobre redes de sociabilidade como forma de associativismo e de aproximação dos recursos de poder político pela via participativa.

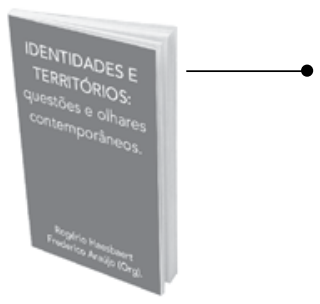

IDENTIDADES E TERRITÓRIOS: questões e olhares contemporâneos. Rogério Haesbaert; Frederico Araújo (Org). Rio de Janeiro: Access, 2007. 136 p.

Neste livro, o estudo sobre as redes está associado a três temáticas gerais, cada uma delas constituindo uma parte do livro - a filosofia, a ética e a estética da rede. Os autores exploram as idéias de território e de multiterritorialidade como uma alternativa para a compreensão das complexas relações espaciais do mundo contemporâneo. O livro reúne artigos que permitem compreender a noção de rede para um público amplo e transdisciplinar. 